\title{
Neonatal Hypothyroidism Affects the Timely Expression of Myelin-associated Glycoprotein in the Rat Brain
}

\author{
Angeles Rodriguez-Peña, Nieves Ibarrola, Miguel Angel Iñiguez, Alberto Muñoz, and Juan Bernal \\ Instituto de Investigaciones Biomédicas, Consejo Superior de Investigaciones Científicas, \\ Facultad de Medicina, Universidad Autónoma de Madrid, 28029 Madrid, Spain
}

\begin{abstract}
Congenital hypothyroidism strongly affects myelination. To assess the role of thyroid hormone on myelin gene expression, we have studied the effect of hypothyroidism on the steady state levels of myelin-associated glycoprotein (MAG) and its mRNA in rat brain during the first postnatal month. As studied by immunoblot analysis of several brain regions, MAG increased from days 10-15 onwards, reaching constant levels by days 20-25. Hypothyroid samples showed a delay in the accumulation of MAG that was more severe in rostral regions, such as cortex and hippocampus. The effect of hypothyroidism on the accumulation of the protein correlated with mRNA levels. MAG mRNA started to accumulate in the cerebrum of normal animals by postnatal day 7 , reaching maximal levels by day 20 . Hypothyroid rats showed a delay of several days in the onset of mRNA expression, increasing thereafter at the same rate as in normal animals, and eventually reaching similar values. When individual brain regions were analyzed, we found strong regional differences in the effect of hypothyroidism. The cerebral cortex was most affected, with messenger levels lower than in normal animals at all ages. In more caudal regions differences between control and hypothyroid rats were evident only at the earlier stages of myelination, with spontaneous recovery at later ages. By run on analysis, we found no differences in transcriptional activities of the MAG gene in normal, hypothyroid, or T4-treated rats. Therefore, the effects of hypothyroidism on MAG mRNA and protein levels were most likely caused by decreased mRNA stability. We propose that thyroid hormone contributes to enhanced myelin gene expression by affecting the stability of newly transcribed mRNA in the early phases of myelination. (J. Clin. Invest. 1993. 812-818.) Key words: myelination • development $\bullet$ cretinism • oligodendrocytes $\bullet$ mRNA stabilization
\end{abstract}

\section{Introduction}

Among the most dramatic and less understood actions of thyroid hormones are those exerted on brain development. Con-

Portions of this work have been presented in part at the Keystone Symposium for Cellular and Molecular Biology, Tammaron, CO, 8-15 March 1991, and at the 19th Meeting of the European Thyroid Association, Hannover, Germany, 25-30 August 1991.

Address correspondence to Dr. Juan Bernal, Instituto de Investigaciones Biomédicas, C/Arturo Duperier 4, 28029 Madrid, Spain.

Received for publication 8 November 1991 and in revised form 5 October 1992.

J. Clin. Invest.

(c) The American Society for Clinical Investigation, Inc.

0021-9738/93/03/0812/07 \$2.00

Volume 91, March 1993, 812-818 genital hypothyroidism in the human being may lead to mental deficiency and other neurological abnormalities. In experimental animals such as the rat, the deleterious effects of thyroid hormone deprivation during the fetal and neonatal periods on brain maturation have also been extensively documented (for reviews, see references 1-4).

The molecular basis of thyroid hormone action on the brain remain largely ignored. The physiological effects of thyroid hormone are the end result of the regulation of a series of specific genes $(5,6)$ mediated through receptors of the erbA family of nuclear proteins acting as ligand-dependent transcription factors (5-9). Both receptor binding activity and the mRNAs coding for two of the three known forms of thyroid hormone receptor, namely $\alpha-1$ and $\beta-1 \mathrm{c}-e r b A s$ have been demonstrated in rat brain, and a specific temporal and regional distribution pattern has been described by hybridization histochemistry in adult and developing animals $(10,11)$. Therefore it is likely that the brain effects of thyroid hormone, as in other organs, are also caused by the control of expression of specific brain genes. However, until recently, no genes expressed in the nervous system have been shown to be regulated at the pretranslational level by thyroid hormone (12). In particular, despite the known effects of thyroid hormone on myelination $(1-4,13-18)$, there are few data on the role and mechanism of thyroid hormone action in the regulation of myelin gene expression in vivo. Our laboratory has recently shown that genes encoding myelin proteins are affected by hypothyroidism at the pretranslational level (12). For one of the abundant structural proteins of myelin, the basic protein (MBP), ${ }^{1}$ thyroid hormone has been proposed to act at the transcriptional (19), or posttranscriptional levels (20).

Myelin is a multilamelar membrane structure surrounding many axons in the central and peripheral nervous system (21$24)$. Central myelin is produced by differentiated oligodendrocytes and consists mainly of lipids (75\%) and proteins (25\%). A minor component of these proteins is myelin-associated glycoprotein (MAG), which comprises $\sim 1 \%$ of central myelin proteins, and is present in periaxonal membranes of uncompacted myelin. MAG is a member of the immunoglobulin superfamily, with strong homologies with cell adhesion molecules such as N-CAM, L1 (Ng-CAM), and J1 $(21,25,26)$. In hypomyelinating mutant mice (quaking), a splicing defect of the MAG gene has been found (27), and direct proof that binding of oligodendrocytes to neurons is mediated by MAG has been obtained (28). From its cell adhesion properties, the early expression of MAG is proposed to play a critical role in myelination, by establishing homotypic interactions among

1. Abbreviations used in this paper: MAG, myelin-associated glycoprotein; MBP, myelin basic protein; MMI, methylmercaptoimidazol; P5, postnatal day 5 . 
oligodendrocytes, or heterotypic interactions between oligodendrocytes and neurons $(25,26)$.

In view of the likely important role of MAG expression in the initial steps of myelination, we have studied the temporal pattern of MAG gene expression during the neonatal period in normal and hypothyroid rats. We find that in the absence of thyroid hormone, as occurs in neonatal hypothyroidism, the accumulation of MAG mRNA in the brain is delayed several days leading to a transient decrease of MAG $\mathrm{mRNA}$ and protein in most brain regions examined. The results suggest that thyroid hormones are needed for the timely expression of MAG acting at a posttranscriptional level. Among other possibilities, it is likely that thyroid hormone act by stabilizing newly transcribed MAG mRNA during the early phases of myelination.

\section{Methods}

Handling of animals and measurement of thyroid hormones. Wistar rats raised in our animal facilities have been used throughout these studies. To induce fetal and neonatal hypothyroidism, drinking water containing $0.02 \%$ methylmercaptoimidazol (MMI) was administered to pregnant rats starting from the 9 th $\mathrm{d}$ after conception and was continued until the end of the experiments. In addition to MMI treatment, and to ensure cerebral hypothyroidism, the neonates were surgically thyroidectomized on postnatal day 5 (P5).

Thyroid hormones were measured in individual cortices of normal and hypothyroid rats on P5 and P20. On P5, hypothyroidism was caused by MMI treatment only, as described above, whereas on P20, hypothyroidism was the combined result of MMI treatment plus surgical thyroidectomy performed $15 \mathrm{~d}$ before. Tissue extraction and radioimmunoassay procedures were as described by Morreale de Escobar et al. (29).

Immunoblots. MAG protein abundance was estimated as follows: brain tissue was homogenized in the cold in 4 vol of PBS. To $0.5-\mathrm{ml}$ aliquots of the homogenates was added $0.5 \mathrm{ml}$ of SDS extraction buffer $(0.125 \mathrm{M}$ Tris- $\mathrm{HCl}, \mathrm{pH} 6.8,4.6 \%$ SDS, and $10 \%$ beta mercaptoethanol), and the mixture was vortexed vigorously, boiled for $2 \mathrm{~min}$, and centrifuged in an Eppendorf centrifuge for $5 \mathrm{~min}$. Aliquots of the supernatants containing $10 \mu \mathrm{g}$ of protein were electrophoresed in $7.5 \%$ polyacrylamide gels by the Laemli method, and transferred to nitrocellulose using a semidry transfer apparatus (Pharmacia LKB Biotechnology Inc., Piscataway, NJ) at $1 \mathrm{~mA} / \mathrm{cm}^{2}$ for $90 \mathrm{~min}$. The filters were washed and blocked with blotto ( $5 \%$ skimmed milk in PBS). The polyclonal MAG antibody, P5, directed against the COOH-terminal portion of clone 1B235/MAG (25) was a gift of Dr J. G. Sutcliffe (Research Institute of Scripps Clinic, La Jolla, CA). The antibody was used at 1:5,000 dilution. For the color reaction we used the alkaline phosphatase kit from Promega (Madison, WI) following the manufacturer's instruction.

Slot and Northern blots. Total RNA was prepared (30) from different brain regions at different times during postnatal development and $\operatorname{poly}(\mathrm{A})^{+}$RNA was further purified after oligo(dT) cellulose chromatography (31). Slot and Northern blots were performed on nylon (Nytran; Schleicher \& Schuell, Inc., Keene, NH). For slot blotting, 1, 2, and $3 \mu \mathrm{g}$ of poly (A $)^{+}$RNA were applied to the filters using a slot blot apparatus Bio Rad Laboratories Inc., Hercules, CA). Samples were treated as described (32). For Northern blots, $20 \mu \mathrm{g}$ of total RNA was fractionated on formaldehyde-agarose gels and transferred to the filters using standard techniques (32). RNA concentrations in the samples were measured by absorbance at $260 \mathrm{~nm}$, and an aliquot of the RNA preparation was electrophoresed in agarose minigels and visualized by ethidium bromide staining to control for RNA integrity. After transfer, the nylon filters were stained with methylene blue (33). The intensity of stained $18 \mathrm{~S}$ and $28 \mathrm{~S}$ ribosomal RNAs gave a direct comparison of the relative amounts of RNA applied to the gels. In some experiments, and to further control for integrity and amount of RNA present in the filters, these were hybridized with a cDNA probe encoding cyclophilin. Cyclophilin mRNA levels are constant in the brain during development (34) and thyroid manipulations have no effect (12). Filters were hybridized at $42^{\circ} \mathrm{C}$ in $3 \times \operatorname{SSC}(1 \times \mathrm{SSC}=0.15 \mathrm{M} \mathrm{NaCl}, 0.015 \mathrm{M} \mathrm{Na}$ citrate), $5 \times$ Denhardt's solution $(1 \times$ Denhardt's solution $=0.1 \%$ Ficoll, $0.1 \%$ polyvinylpirrolidone, $0.1 \% \mathrm{BSA}$ ) and $50 \%$ formamide for $20 \mathrm{~h}$, and washed at $65^{\circ} \mathrm{C}$ in $0.2 \times \mathrm{SSC}, 0.5 \% \mathrm{SDS}$, before exposure on $\mathrm{x}$-ray films.

As a probe, we used the MAG clone 1B236-18 (25) containing the full-length rat cDNA; labeling was by either the random priming method or by nick translation following standard techniques (32). $\left[{ }^{32} \mathrm{P}\right] \mathrm{dCTP}$ ( sp act $>3,000 \mathrm{Ci} / \mathrm{mmol}$; from New England Nuclear, Boston, MA, or Amersham Corp., Arlington Heights, IL) was used for the labeling reactions. Specific activities of the radioactive probes were above $10^{8} \mathrm{dpm} / \mu \mathrm{g}$ DNA.

Run-on assays. To measure the transcriptional activity of the MAG gene under different thyroidal status, we isolated cell nuclei from cerebral corteces or whole cerebra of normal, hypothyroid, and T4-treated hypothyroid rats. Nuclei were isolated after homogenizing the tissues in $0.25 \mathrm{M}$ sucrose, $1 \mathrm{mM} \mathrm{MgCl} 2,1 \mathrm{mM} \mathrm{CaCl} 2,10 \mathrm{mM}$ Tris- $\mathrm{HCl}, \mathrm{pH}$ 7.4, containing $0.5 \%$ NP-40 (Sigma Chemical Co., St. Louis, MO) using a Dounce homogenizer at $0^{\circ} \mathrm{C}$. Run-on reactions were performed basically according to (35) using $\left[\alpha{ }^{32} \mathrm{P}\right]$ UTP and nuclei equivalent to $100 \mu \mathrm{g}$ of DNA. The probes were $5 \mu \mathrm{g}$ of linearized MAG or cyclophilin plasmid DNA immobilized on nitrocellulose filters after denaturation in $\mathrm{NaOH}$. Linearized pBR322 was also present on the filters to control for background hybridization. Labeled RNA was purified by phenol/chloroform extraction after addition of 3 vol of guanidine isothiocyanate solution (30) and isopropanol precipitation. Unincorporated label was removed by centrifugation through Sephadex G-50 spun columns. Recovery as high molecular weight material from the columns was $7 \%$ of the total radioactivity present in the run-on reactions. Hybridizations were performed in $0.2 \mathrm{M}$ sodium phosphate buffer, pH 7.2, 1 mM EDTA, 7\% SDS, and 45\% formamide containing $250 \mu \mathrm{g} / \mathrm{ml}$ Escherichia coli transfer RNA as a carrier, at $50^{\circ} \mathrm{C}$ for $2 \mathrm{~d}$. After hybridization the filters were washed in $40 \mathrm{mM}$ sodium phosphate buffer, $\mathrm{pH} 7.2$, containing $1 \%$ SDS at $65^{\circ} \mathrm{C}$. Control of MAG RNA hybridization to the immobilized cDNA on the filters was carried out by including a ${ }^{3} \mathrm{H}$-labeled MAG mRNA. This was synthesized by transcribing a full-length MAG cDNA template cloned in pGEM4 with SP6 polymerase in the presence of $\left[{ }^{3} \mathrm{H}\right]$ UTP using standard methods (32). Synthesis of the transcript was assessed by TCA precipitation and agar gel electrophoresis. $50,000 \mathrm{cpm}$ of the tritiated MAG mRNA was mixed with the ${ }^{32} \mathrm{P}$-labeled RNA from each experimental group before adding to the filters. After hybridization and washing, the filters were exposed to $\mathrm{x}$-ray films, and the bands were cut out to measure ${ }^{32} \mathrm{P}$ and ${ }^{3} \mathrm{H}$.

Statistical analysis. Data from MAG mRNA abundance as measured by slot blots were submitted to two-way analysis of variance. Significance of differences between groups was assessed using the protected least significance differences test, and considered significant when $P<0.05$. All these calculations were performed as described by Snedecor and Cochran (36).

\section{Results}

T4 and T3 concentrations in the cerebral cortex of normal and hypothyroid rats. To determine whether our protocol for inducing cerebral hypothyroidism resulted in low concentrations of thyroid hormones, we determined $\mathrm{T} 4$ and $\mathrm{T} 3$ concentrations by RIA in ethanolic extracts of total cerebral cortex from normal and hypothyroid rats killed at 5 and $20 \mathrm{~d}$ of age. T4 and T3 determinations were performed in the cerebral cortex, since T4 5'-deiodinase is abundant in this part of the brain, and its activity increases in hypothyroid animals (37). Therefore, 
brain T3 levels may be normal even if plasma and other tissues show low levels of the hormone. Fig. 1 shows that T4 increased in normal animals from $0.9 \mathrm{ng} / \mathrm{g}$ on P5 to $2 \mathrm{ng} / \mathrm{g}$ on P20 $(P$ $<0.001)$. After MMI treatment to the dams from the 9 th $d$ after conception, T4 levels in the cerebral cortex of the offsprings $5 \mathrm{~d}$ after birth was $0.1 \mathrm{ng} / \mathrm{g}$. T4 increased in hypothyroid, $\mathrm{P} 20$ animals, but its concentration was still only $0.2 \mathrm{ng} / \mathrm{g}$; i.e., 10-fold lower than in normal animals of the same age. T3 concentrations increased in normal animals from 3.2 to 3.8 $\mathrm{ng} / \mathrm{g}(P<0.01)$ from P5 to P20. In hypothyroid animals, T3 concentrations were 0.14 and $0.21 \mathrm{ng} / \mathrm{g}$, respectively. These results demonstrate that the combined treatment of chemical and surgical thyroidectomy ensured low tissue levels of T4 and T3 throughout the developmental period studied.

Developmental expression of $M A G M R N A$. The expression of the MAG gene during development was studied in slot blots of poly $(A)^{+}$RNA samples isolated from cerebra of normal and hypothyroid animals at different times after birth. 1-, 2-, and 3- $\mu \mathrm{g}$ aliquots of RNA obtained from individual rats were applied to the filters, which were hybridized with a MAG cDNA probe. Fig. 2 shows densitometric measurements of the corresponding signals in the radioautograms from individual animals. MAG mRNA was not detected during the first 5-7 d after birth. In normal animals, it increased in abundance, thereafter reaching maximal levels around day 20 . In hypothyroid animals, MAG mRNA accumulation in total brain also increased with age, but more slowly and with an apparent delay when compared with normal animals. The data points were computer-fitted to generate the curves depicted, with signifcance levels of $P<0.01$ for the control curve, and $P<0.001$ for the hypothyroid curve. Two-way analysis of variance taking as factors age and thyroid status, indicated that as a whole the data from hypothyroid animals were different from the controls $(F$ ratio $=9.0, P=0.008)$. When individual time points were considered, there were no significant differences between hypothyroid and control values beyond $20 \mathrm{~d}$ of age, when the plateau of MAG mRNA was attained.

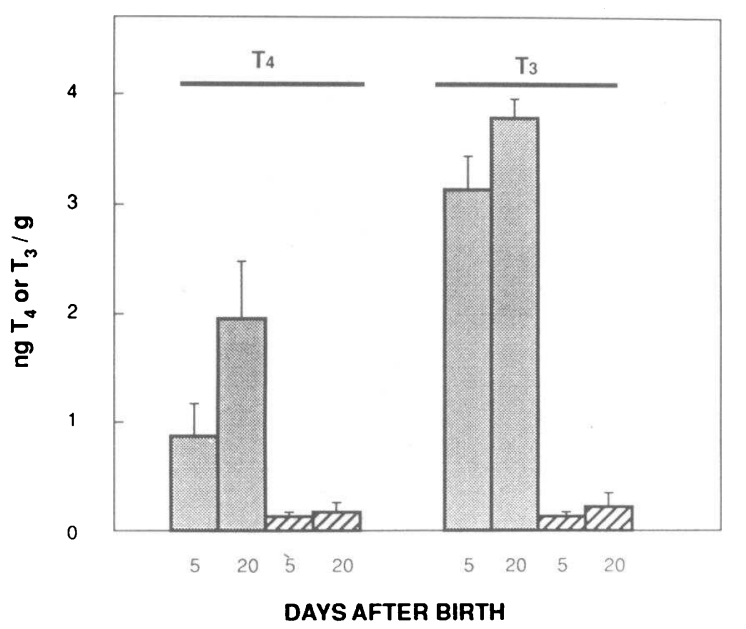

Figure 1. T4 and T3 concentrations in the cerebral cortices of normal and hypothyroid rats. T4 and T3 were measured by radioimmunoassay in extracts from the cerebral cortices of normal ( solid bars) and hypothyroid (hatched bars) rats at 5 and $20 \mathrm{~d}$ after birth. Differences between normal and hypothyroid animals were statistically signifcant, with $P<0.001$.

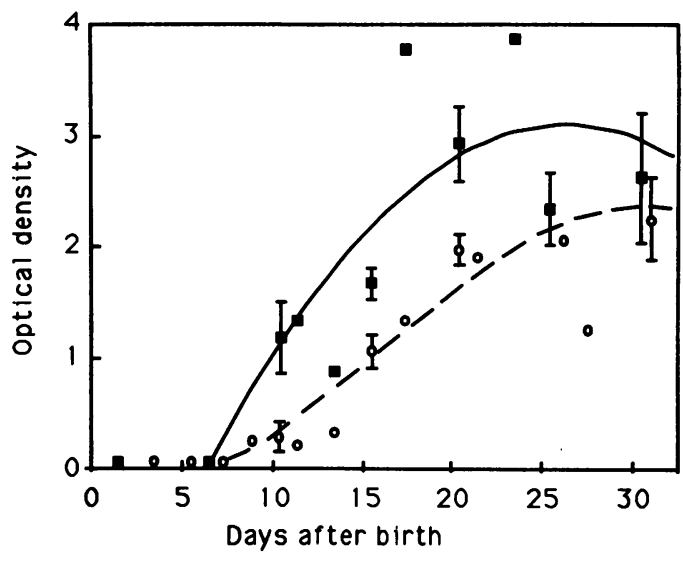

Figure 2. Developmental pattern of MAG mRNA expression in normal and hypothyroid rats. MAG mRNA was measured in slot blots using poly (A) ${ }^{+}$RNA purified from whole cerebra of normal (black squares and solid line) and hypothyroid (open dots and dotted line) animals. The data represented are individual values, or mean $\pm \mathrm{SD}$ of data from three different animals.

Temporal and regional effects of hypothyroidism on $M A G$ gene expression. The results described above suggest that a major effect of hypothyroidism on MAG gene expression is a transient delay in the normal developmental pattern. However, myelination has not the same timing in all brain regions, proceeding normally from caudal to rostral areas (38). In other words, in the above experiment, we examined a mixture of widely heterogeneous regions at different stages of myelination. Therefore, we examined the effect of hypothyroidism on the regional pattern of expression of the MAG gene during the first month of life. Brains from normal and hypothyroid animals were individually dissected into regions including cerebral cortex, striatum, hippocampus, mesencephalon, and hypothalamus. RNA was isolated from individual cortices or from pooled regions as described, and the mRNA encoding MAG,

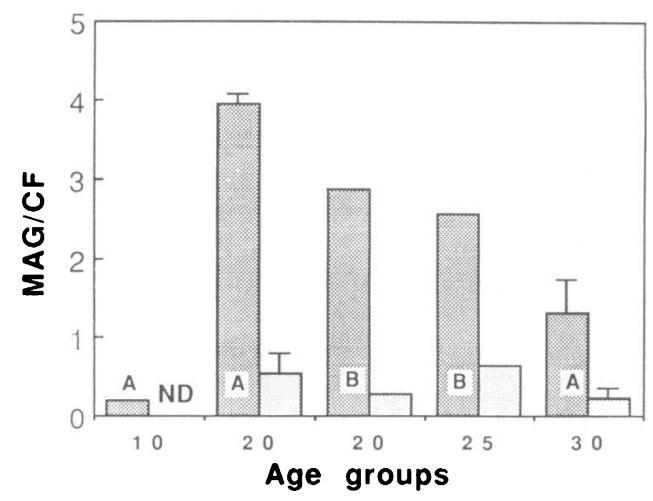

Figure 3. Effect of hypothyroidism on MAG mRNA abundance in the cerebral cortex. Total RNA was purified from individual cortices at 10,20 , and $30 \mathrm{~d}$ (experiment $A$ ) or at 20 and $25 \mathrm{~d}$ (experiment $B$ ) after birth, and analyzed by Northern blotting using a labeled MAG cDNA as a probe. The filter was rehybridized with a probe for cyclophilin, an ubiquitous mRNA unaffected by hypothyroidism (12), and the ratio MAG to cyclophilin was measured. In experiment $A$, we processed three individual samples from each group, and the data are mean \pm SD of three values. MAG mRNA was not detected on day 10 (ND). In experiment $B$, we analyzed pools of two samples from either normal or hypothyroid animals. 
was identified by Northern blotting. Fig. 3 shows the results obtained using cerebral cortices of normal and hypothyroid rats of different ages. (The rat cerebral cortex contains an estimated 1.1 million callosal fibers, from which about two thirds are myelinated. (38a) These fibers enter the cortical plate around day 3 after birth, and the adult pattern is attained at the end of the 1st wk of life. In our experiments, cortex MAG arises from the cortex proper and from the subcortical white matter.) Two different sets of data are represented in the figure. Data labeled $A$ are the mean \pm SD of three individual cortices from each age group. Data labeled $B$ are single determinations from pools of two different cortices. Results in each case are very similar. The MAG mRNA bands were quantified by densitometry after Northern blotting and related to the intensity of a cyclophilin mRNA control. On day, 10 little MAG mRNA was present in normal cortex, and it was undetectable in the cortex of hypothyroid animals. At any subsequent time, hypothyroid levels were reduced by $\sim 80 \%$ or more compared to normal values.

Fig. 4 shows Northern blot patterns of MAG mRNA in four

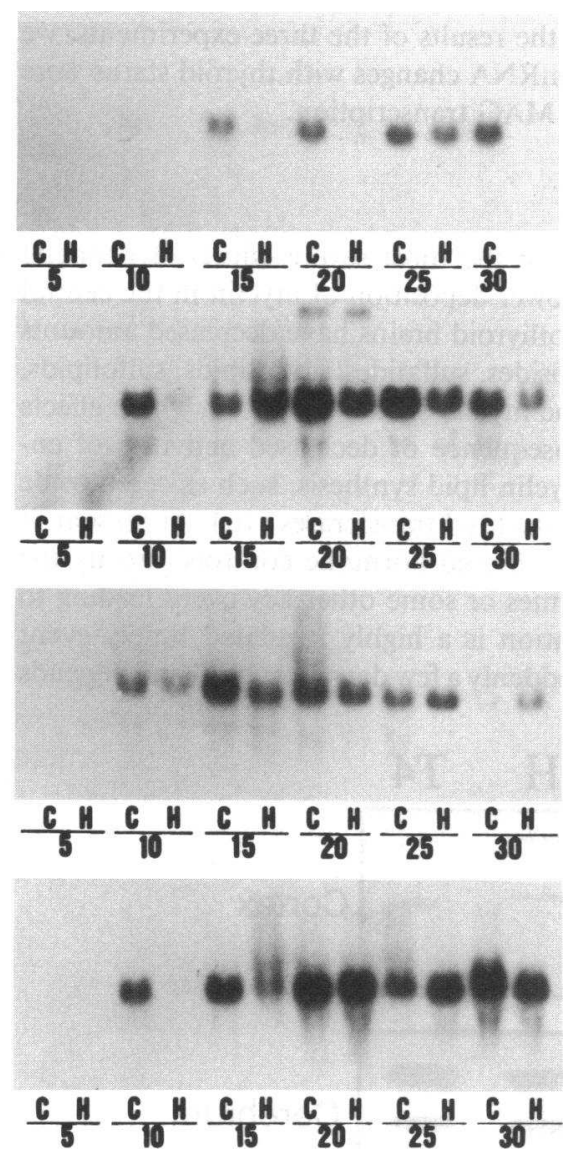

HIPPOCAMPUS

\section{STRIATUM}

\section{MESENCEPHALON}

HYPOTHALAMUS

Figure 4. Developmental pattern of MAG mRNA in brain regions. Total RNA was purified from pooled (three samples for each pool) regions individually dissected from the brains of normal $(C)$ and hypothyroid $(H)$ rats at different days after birth. After transfer the nylon filters were stained to visualize ribosomal RNA to control for integrity and amount of RNA present in each lane (not shown). The lanes contained similar amounts of RNA, except for $\mathrm{C} 15$ and $\mathrm{H} 15$ in the striatum, which contained lower and higher amounts, respectively, and $\mathrm{H} 15$ in the hypothalamus that contained much lower amount of RNA than calculated. different regions of the brain from normal controls $(C)$ and hypothyroid $(H)$ rats throughout the first month of life, at 5 , $10,15,20$, and $30 \mathrm{~d}$ of age. Pools of three samples were processed in these experiments. The results show that the effect of hypothyroidism depends on the region examined and the age of the animals. In the hippocampus, maximal amounts of MAG mRNA were attained at around $25 \mathrm{~d}$ of age in normal animals. In hypothyroid animals, however, lower levels were found at all ages, and by $25 \mathrm{~d}$, normal amounts were not yet attained. In contrast to the cortex and hippocampus, the effect of hypothyroidism in the striatum, mesencephalon, and hypothalamus was evident only at the earliest stages of myelination, from the 10th to the 15 th postnatal days.

Patterns of $M A G$ expression in normal and hypothyroid animals. Fig. 5 shows the results of MAG expression in immunoblots of different regions of normal and hypothyroid brains. Different ages along the neonatal period are represented in the figure. The P5 antibody used for the immunoblots detected a main 100-116 kD protein band that was not present in the brain before myelination. This band was not detected in control experiments using extracts from other organs such as liver or kidney (not shown). The blots were overdeveloped to in-
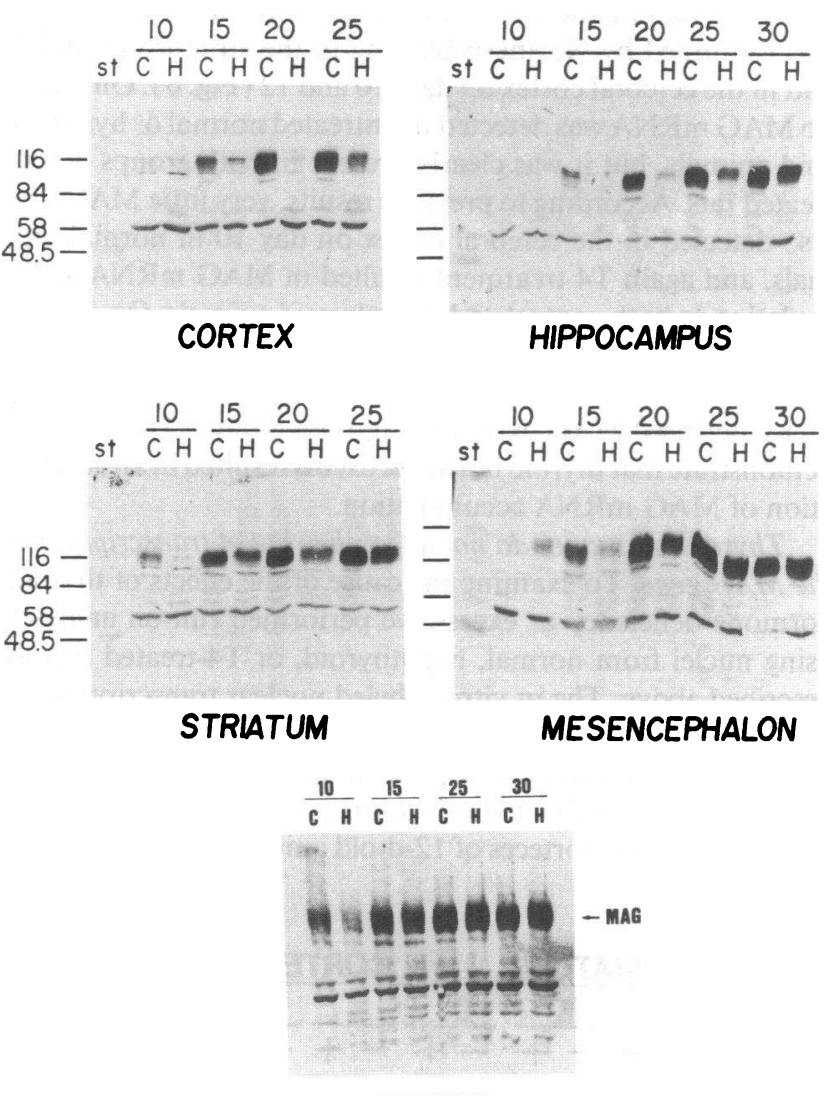

CEREBELLUM

Figure 5. Developmental pattern of MAG in normal and hypothyroid rats. Protein extracts from different brain regions at different ages were electrophoresed in denaturing polyacrylamide gels and electroblotted to nitrocellulose. The filters were probed with a polyclonal antibody directed against the $\mathrm{COOH}$-terminal portion of MAG. Shown are the results obtained using three pooled samples from normal $(C)$ or hypothyroid $(H)$ killed at $10,15,20,25$, and $30 \mathrm{~d}$ of postnatal age. MAG was present as a broad protein band spanning in size from 100 to $116 \mathrm{kD}$. 
crease the intensity of a nonspecific band of $58 \mathrm{kD}$ that was not altered by hypothyroidism, and thus served as control for the amount of protein loaded on the gels. In the cortex and hippocampus of normal rats, MAG was almost undetectable on P10, and was clearly present on P15. It increased subsequently reaching high levels on P25 and P30. In striatum and mesencephalon, MAG was already present on P10, and increased thereafter reaching maximal levels on P20-P25. There was a clear effect of hypothyroidism in the cerebral cortex, hippocampus and striatum, with very low levels of MAG up to P20 compared with normal animals. In hypothyroid animals, levels of MAG increased after P20 and, therefore, the differences with normal animals tended to disappear. The effect of hypothyroidism in the mesencephalon was less evident, and there was somewhat less MAG in the hypothyroid samples of P15 and P20. The transient effect of hypothyroidism on MAG protein was also evident in the cerebellum, where only on P10 there was clearly a lower amount of protein in hypothyroid rats.

Hyperthyroidism accelerates $M A G M R N A$ expression. If thyroid hormones are involved in the timing of MAG expression, it is likely that contrary to the effect of hypothyroidism, thyroid hormone excess induced a precocious expression of the MAG gene. To study this possibility, normal or hypothyroid animals were administered $5 \mu \mathrm{g}$ of $\mathrm{T} 4$ per rat during $5 \mathrm{~d}$ before death to evaluate the effect of hyperthyroidism. MAG mRNA was examined by Northern blotting in the striatum on day 7 and in the cerebral cortex on days 10 and 12 (Fig. 6). On day 7 , no MAG mRNA was detected in untreated normal or hypothyroid animals, but it was clearly present in both groups of T4treated rats. According to previous results, very little MAG was also detected in the cerebral cortex on day 10 in normal animals, and again T4 treatment resulted in MAG mRNA accumulation in both control and hypothyroid animals. On day 12 , MAG was already clearly expressed in the cortex of normal rats, but was almost absent in hypothyroid animals. T4 treatment increased MAG expression in both groups. These results demonstrate that thyroid hormone excess resulted in an acceleration of MAG mRNA accumulation.

Thyroid hormones do not affect the rate of transcription of the $M A G$ gene. To examine the cause of the effects of thyroid hormone deficiency or excess, we performed run-on analyses using nuclei from normal, hypothyroid, or T4-treated rats as described above. The in vitro-labeled nuclear transcripts were hybridized with full-length cDNAs encoding MAG, cyclophilin as a thyroid hormone independent message, and pBR322 as control for nonspecific hybridization. As a source of nuclei we first used cerebral corteces of 12-d-old animals as in the experi-

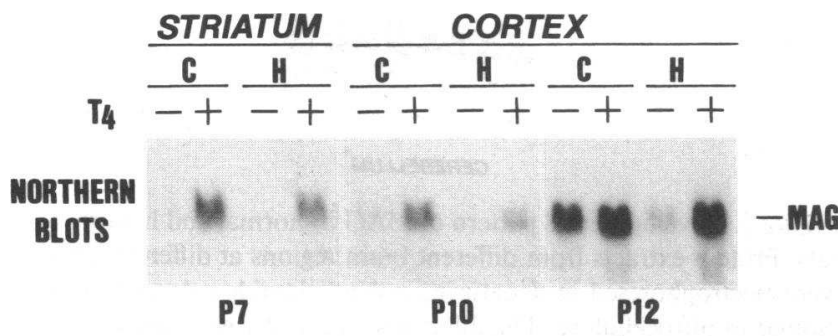

Figure 6. Effect of hypothyroidism on MAG mRNA accumulation. Hypothyroid and control animals were treated $(+)$ or untreated $(-)$ with a single daily dose of $5 \mu \mathrm{g}$ T4 during the last $5 \mathrm{~d}$ before death. Rats were killed at 7, 10, and $12 \mathrm{~d}$ and MAG mRNA was measured by Northern blotting in striatum ( $7 \mathrm{~d}$ ) or cerebral cortex ( 10 and $12 \mathrm{~d}$ ). ment illustrated in Fig. 6. A representative result from one of two independent experiments is illustrated in Fig. $7 \mathrm{~A}$, showing no obvious significant differences among the three experimental groups. The mean MAG/cyclophilin ratios obtained after densitometry for the two experiments were 1.1 (control), 1.3 (hypothyroid) and 0.8 (T4 treated). We also used nuclei from total cerebra of 13-d-old animals, which were expected to be more actively transcribing the MAG gene. To better quantify the results and to correct for eventual differences in the amount of MAG RNA hybridized to the respective probes, we included a $\left[{ }^{3} \mathrm{H}\right]$ MAG mRNA in the hybridization mixture. After hybridization and exposure to $x$-ray films, the bands were cut out and radioactivity was measured. The results shown in Fig. $7 \mathrm{~B}$, again did not reveal significant differences between normal and hypothyroid animals. The signal for T4-treated animals was slightly higher, both in the MAG probe and the CF control probe. After quantification of the data, taking into account the total amount of ${ }^{32} \mathrm{P}$ present in the hybridization mixtures (1.4, 1.6, and 2.1 million cpm for control, hypothyroid, and T4 treated, respectively) and the percentage $\left[{ }^{3} \mathrm{H}\right]$ MAG mRNA hybridized ( control $=4.27$, hypothyroid $=2.52, \mathrm{~T} 4$ treated $=4.07$ ), the percent of total ${ }^{32} \mathrm{P}$ hybridized was 0.20 (control rats), 0.24 (hypothyroid rats), and 0.18 (T4-treated rats). Taken together from the results of the three experiments, we conclude that MAG mRNA changes with thyroid status were not caused by altered MAG transcription.

\section{Discussion}

It is known that one of the most severe effects of neonatal hypothyroidism is a lower deposition of myelin in the central nervous system. Hypothyroid brains have decreased amounts of cholesterol, cerebrosides, sulfatides, glycolipids, sulfolipids, and gangliosides in the myelin sheaths (13-18). These effects appear to be the consequence of decreased activities of enzymes involved in myelin lipid synthesis, such as cerebroside sulfotransferase and galactosyl transferases (16). At present, it is not known whether thyroid hormone controls directly the activity of these enzymes or some other key event leading to myelination. Myelination is a highly regulated timely event that in the rat starts suddenly a few days after birth and depends
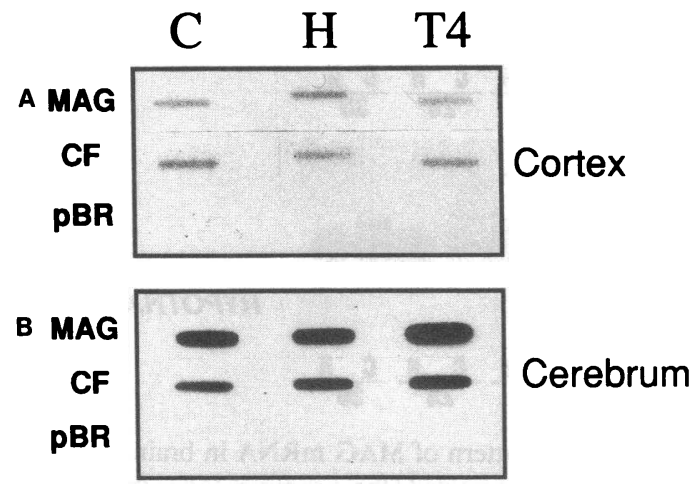

Figure 7. Run-on analysis of the effect of hypothyroidism and T4 treatment on the MAG gene. Run-on analyses were performed using nuclei from pooled (three rats per pool) cerebral cortices $(A)$, or cerebra ( $B$ ) of normal, hypothyroid or T4 treated rats as described above. Cortex nuclei were from 12-d-old animals and cerebral nuclei from 13-d-old animals. As probes we used MAG, cyclophilin (CS), and pBR322. No hybridization was obtained using nuclei transcribed in the presence of alpha-amanitin (not shown). 
on the proper differentiation of oligodendrocytes from its $\mathrm{O} 2 \mathrm{~A}$ precursor cells. Oligodendrocyte differentiation is determined by the concerted actions of fibroblast and platelet-derived growth factors (39). As shown in this paper, thyroid hormone is also required for full expression of at least one of the differentiated properties of oligodendrocytes; i.e. expression of the MAG gene, and its main role is to ensure an accurate timing of gene expression.

Hypothyroidism led to a delay in the pattern of MAG accumulation in different brain regions. The regional effect of hypothyroidism reflects the fact that myelination does not proceed simultaneously throughout the brain. Normally, the myelination wave starts in caudal regions and proceeds towards rostral areas. This pattern has been deduced from studies of myelin mRNA accumulation by either Northern blots or in situ hybridization (38). We show here that regions that myelinate last are more affected by hypothyroidism than those of earlier myelination. From the patterns of expression of MAG mRNA or protein, we conclude that caudal regions such as cerebellum, hypothalamus, and mesencephalon present a transient alteration with spontaneous recovery beyond days 15-20 after birth. This pattern is similar to the effect of hypothyroidism on microtubule-associated protein- 2 in the cerebellum (40). In contrast, normalization in the hippocampus and striatum did not occur before days $25-30$, and myelination in the cerebral cortex was impaired beyond the first month of life.

The timing control by thyroid hormone is also supported by the effect of hyperthyroidism. In the presence of an excess of thyroid hormone, MAG expression was accelerated in previously normal or hypothyroid animals. This is in agreement with other results reporting an acceleration of myelination in hypothyroid rats, with precocious increases of myelin enzyme activities (41). A clear timing control by thyroid hormone also occurs during cerebellar development (42), in the transition between the juvenile and adult forms of Tau (43), in the expression of neuronal markers such as synapsin I in culture (44), during development of the organ of Corti (45), or in the appearance of enzymes during development of cholinergic neurons (46).

The action of thyroid hormone on MAG expression could be exerted directly by the interaction of the thyroid hormone receptor with promoter sequences in the MAG gene. Although we have detected no labeling in white matter by in situ hybridization using c-erbA probes (11), oligodendrocytes in primary cultures have been shown to express the thyroid hormone receptor (47). T3 receptors have recently been demonstrated in glial cells isolated from rat brain during the neonatal period (48). Highest receptor density was found in the cerebral cortex. The rest of brain regions contained much fewer amounts of receptor and, contrary to the cortex, receptor density declined during development, especially in the cerebellum. These data agree with the transient dependency of myelin genes during the early stages of myelination reported in this paper. Recently, Nikodem and associates have described the presence of sequences in the promoter region of myelin basic protein that have functional characteristics of a thyroid hormone responsive element (19). In contrast, we find that neither hypothyroidism nor thyroid hormone treatment modified significantly the rates of transcription of the MAG gene. Therefore, hypothyroidism could have led to a decreased stability of MAG mRNA. An increased degradation in the presence of an equal rate of synthesis would be predicted to result in a delay of mRNA accumulation. Others have also shown an effect of thy- roid hormone on MBP gene expression in aggregating brain cell cultures, which is mediated through an action on mRNA stability rather than transcription (20). The fact that the rate of transcription was not modified is also an argument against a possible effect on the number of oligodendrocytes, which is in agreement with the known lack of effect of thyroid hormone on oligodendrocyte proliferation (49). Other reports have also suggested that the number of oligodendrocytes does not change in hypothyroidism (50). Although an effect on mRNA transport from the nucleus to the cytoplasm cannot be discarded at present, it is likely that thyroid hormone is required to stabilize newly transcribed MAG mRNA during the earlier phases of myelination to allow for a rapid accumulation of the transcripts and protein production. This is not surprising, in view of the fact that although the main control on myelin gene expression is exerted at the level of transcription by oligodendrocyte-specific transcription factors (21-24), there is also control at the posttranscriptional level. For example, glucocorticoids posttranscriptionally regulate the expression of basic protein and proteolipid protein $(51)$. The deficits of myelination of the myelin deficient mice $(\mathrm{mld})$ are also caused by posttranscriptional events (52).

As we have shown previously (12), other oligodendrocyte specific genes as MBP and proteolipid protein are also affected by neonatal hypothyroidism. The question arises as to whether thyroid hormone influences the expression of each myelin gene by a similar mechanism, or the effects are the end result of the regulation of an as yet unidentified key developmental gene that could be influenced by thyroid hormone itself, or by thyroid hormone-dependent factors, including growth hormone. Whether thyroid hormone acts directly or indirectly, its effect on the expression of MAG would be critical early in myelination. Because of its cell-adhesion properties, its localization in the periaxonal space and uncompacted myelin, and its timing of expression in relation to other myelin proteins (53), MAG has been proposed to establish initial interactions between the oligodendrocyte surface and the axon to be myelinated, and in the maintenance of this interaction.

Independently of the mechanism of action, a delay of myelination, even if transient, would result in serious disturbances of brain maturation, since the normal coordination between axon growth and targeting and myelination will not occur. The altered pattern of myelination should have profound consequences on the hypothyroid brain in terms of neuron performance and development of fiber networks. In addition to its role in myelination, MAG has also neurite outgrowth activity (54), an impairment of which would constitute an additional factor contributing to the complexity and severity of the hypothyroid brain phenotype.

\section{Acknowledgments}

We thank Dr. Gabriella Morreale de Escobar for helpful discussions and determinations of T4 and T3 by RIA. We also thank Dr. J. G. Sutcliffe for the MAG cDNA probe and the MAG antibody.

This work was supported by grants from Direccion General de Investigación Científica y Técnica (PM88-0006), from AntibióticosPharma S.A. (Madrid, Spain), and from the Community of Madrid (C254/90).

\section{References}

1. Eayrs, J. T. 1968. Developmental relationships between brain and thyroid. In Endocrinology and Human Behaviour. R. P. Michael, editor. Oxford University Press, London. 239-255.

2. Legrand, J. 1984. Effects of thyroid hormones on central nervous system. In 
Neurobehavioral Teratology. J. Yanai, editor. Elsevier Science Publishers, Amsterdam. 331-363.

3. Morreale de Escobar, G., F. Escobar del Rey, and A. Ruiz-Marcos. 1983. Thyroid hormone and the developing brain. In Congenital Hypothyroidism. J. H. Dussault and P. Walker, editors. Marcel Decker, Inc., New York. 85-126.

4. Dussault, J. H., and J. Ruel. 1987. Thyroid hormones and brain development. Annu. Rev. Physiol. 49:321-334.

5. Christofer, K. G., and J. M. Holloway. 1990. Regulation of gene expression by the thyroid hormone receptor. Biochim. Biophys. Acta. 1032:157-176.

6. Brent, G. A., D. D. Moore, and P. R. Larsen. 1991. Thyroid hormone regulation of gene expression. Annu. Rev. Physiol. 53:17-35.

7. Evans, R. M. 1988. The steroid and thyroid hormone receptor superfamily. Science (Wash. DC) 240:889-895.

8. Sap, J., A. Muñoz, K. Damm, Y. Goldberg, J. Ghysdael, A. Lentz, H. Beug, and B. Vennström. 1986. The c-erbA protein is a high affinity receptor for thyroid hormone. Nature (Lond.). 324:635-640.

9. Weinberger, C., C. C. Thompson, E. S. Ong, R. Lebo, D. J. Gruol, and R. M. Evans. 1986. The c-erbA gene encodes a thyroid hormone receptor. Nature (Lond.). 324:641-646.

10. Bradley, D. J., W. S. Young III, and C. Weinberger. 1989. Differential expression of alpha and beta thyroid hormone receptor genes in rat brain and pituitary. Proc. Natl. Acad. Sci. USA. 86:7250-7254.

11. Mellström, B., J. R. Naranjo, A. Santos, A. M. Gonzalez, and J. Bernal. 1991. Independent expression of the alpha and beta c-erbA genes in developing rat brain. Mol. Endocrinol. 5:1339-1350.

12. Muñoz, A., A. Rodriguez-Peña, A. Perez-Castillo, B. Ferreiro, J. G. Sutcliffe, and J. Bernal. 1991. Effects of neonatal hypothyroidism on rat brain gene expression. Mol. Endocrinol. 5:273-280.

13. Flynn, T. J., D. S. Deshmukh, and R. A. Pieringer. 1977. Effect of altered thyroid function on galactosyl diacylglycerol metabolism in myelinating rat brain. J. Biol. Chem. 252:5864-5870.

14. Bhat, N. R., G. Subba Rao, and R. A. Pieringer. 1981. Investigations on myelination in vitro: regulation of sulfolipid synthesis by thyroid hormone in cultures of dissociated brain cells from embryonic mice. J. Biol. Chem. 256:1167-1171.

15. Balazs, R., B. W. L. Brooksbank, A. N. Davison, J. T. Eayrs, and D. A. Wilson. 1969. The effect of neonatal thyroidectomy on myelination in the rat brain. Brain Res. 15:219-232.

16. Bhat, N. R., L. L. Sarlieve, G. Subba Rao, and R. A. Pieringer. 1979. Investigations on myelination in vitro: regulation by thyroid hormone in cultures of dissociated cells from embryonic mice. J. Biol. Chem. 254:9342-9344.

17. Shanker, G., A. T. Campagnoni, and R. A. Pieringer. 1987. Investigations on myelinogenesis in vitro: developmental expression of myelin basic protein mRNA and its regulation by thyroid hormone in primary cerebral cell cultures from embryonic mice. J. Neurosci. Res. 17:220-224.

18. Walravens, P., and H. P. Chase. 1969. Influence of thyroid hormone on formation of myelin lipids. J. Neurochem. 16:1477-1484.

19. Farsetti, A., T. Mitsuashi, B. Desvergne, J. Robbins, and V. Nikodem. 1991. Molecular basis of thyroid hormone regulation of myelin basic protein gene expression in rodent brain. J. Biol. Chem. 266:23226-23232.

20. Matthieu, J. M., J. M. Roch, S. Torch, M. Tosic, P. Carpano, L. Insirello, A. M. G. Stella, and P. Honegger. 1990. Triiodothyronine increases the stability of myelin basic protein messenger RNA in aggregating brain cell cultures. In Regulation of Gene Expression in the Nervous System. 59:109-121.

21. Sutcliffe, J. G. 1987. The genes for myelin. Trends Genet. 3:73-76.

22. Lemke, G. 1986. Molecular biology of the major myelin genes. Trends Neurosci. 9:266-270.

23. Campagnoni, A. T., and W. B. Macklin. 1988. Cellular and molecular aspects of myelin protein gene expression. Mol. Neurobiol. 2:41-89.

24. Mikoshiba, K., H. Okano, T. Tamura, and K. Ikenaka. 1991. Structure and Function of Myelin Protein Genes. Annu. Rev. Neurosci. 14:201-217.

25. Lai, C., M. A. Brow, K.-A. Nave, A. B. Noronha, R. H. Quarles, F. E Bloom, R. J. Milner, and J. G. Sutcliffe. 1987. Two forms of 1B236/myelin-associated glycoprotein, a cell adhesion molecule for postnatal neural development, are produced by alternative splicing. Proc. Natl. Acad. Sci. USA. 84:4337-4341.

26. Martini, R., and M. Schachner. 1986. Immunoelectron microscopic localization of neural cell adhesion molecules ( $1, N-C A M$, and MAG) and their shared carbohydrate epitope and myelin basic protein in developing sciatic nerve. J. Cell Biol. 103:239-2448.

27. Fujita, N., S. Sato, T. Kurihara, T. Inuzuka, Y. Takahashi, and T. Miyatake. 1988. Developmentally regulated alternative splicing of brain myelin-associated glycoprotein mRNA is lacking in the quaking mouse. FEBS (Fed. Eur Biochem. Soc.) Lett. 232:323-327.

28. Poltorak, M., R. Sadoul, G. Keilhauer, C. Landa, T. Fahrig, and M Schachner. 1987. Myelin-associated glycoprotein, a member of the L2/HNK-1 family of neural cell adhesion molecules, is involved in neuron-oligodendrocyte and oligodendrocyte-oligodendrocyte interaction. J. Cell Biol. 105:1893-1899.

29. Morreale de Escobar, G., R. Pastor, M. J. Obregon, and F. Escobar de Rey. 1985. Effects of maternal hypothyroidism on the weight and thyroid hormone content of rat embryonic tissues, before and after onset of fetal thyroid function. Endocrinology. 117:1890-1896.
30. Chomczynski, P., and N. Sacchi. 1987. Single step method of RNA isolation by acid guanidinium thiocyanate-phenol-chloroform extraction. Anal. Bio chem. 162:156-159.

31. Aviv, H., and P. Leder. 1972. Purification of biologically active globin messenger RNA by chromatography on oligothymidylic acid. Proc. Natl. Acad. Sci. USA. 69:1408-1412.

32. Sambrook, J., E. F. Fritsch, and T. Maniatis. 1989. Molecular Cloning: A Laboratory Manual. Cold Spring Harbor Laboratory Press, Cold Spring, NY.

33. Herrin, D. L. 1988. Rapid, reversible staining of northern blots prior to hybridization. Biotechniques. 6:196-200.

34. Danielson, P. E., S. Forss-Peter, M. A. Brow, L. Calavetta, J. Douglass, R. J. Milner, and J. G. Sutcliffe. 1988. p1B15: A cDNA clone of the rat mRNA encoding cyclophilin. DNA Cell Biol. 7:261-267.

35. Linial, M., N. Gunderson, and M. Groudine. 1985. Enhanced transcription of c-myc in bursal lymphoma cells requires continuous protein synthesis. Science (Wash. DC). 230:1126-1132.

36. Snedecor, G. W., and W. G. Cochran. 1980. Statistical Methods. Iowa State University Press, Ames, IA. 507 pp.

37. Silva, J. E., and P. S. Mathews. 1984. Production rates and turnover of triiodothyronine in rat-developing cerebral cortex and cerebellum. Responses to hypothyroidism. J. Clin. Invest. 74:1035-1049.

38. Verity, A. N., and A. T. Campagnoni. 1988. Regional expression of myelin protein genes in the developing mouse brain: in situ hybridization studies. $J$. Neurosci. Res. 21:238-248.

38a. Hebel, R., and M. W. Stromberg. 1986. Anatomy and Embryology of the Laboratory Rat. Biomed Verlag, Wörthsee, Germany. 271 pp.

39. Bögler, O., D. Wren, S. C. Barnett, H. Land, and M. Noble. 1990. Cooperation between two growth factors promotes extended self-renewal and inhibits differentiation of oligodendrocyte-type-2 astrocyte (O-2A) progenitor cells. Proc. Natl. Acad. Sci. USA. 87:6368-6372.

40. Silva, J. E., and P. Rudas. 1990. Effects of congenital hypothyroidism on microtubule-associated protein-2 expression in the cerebellum of the rat. Endocrinology. 126:1276-1282.

41. Adamo, A. M., P. A. Aloise, E. F. Soto, and J. M. Pasquini. 1990. Neonatal hyperthyroidism in the rat produces an increase in the activity of microperoxisomal marker enzymes coincident with biochemical signs of accelerated myelination. J. Neurosci. Res. 25:353-359.

42. Nicholson, J. L., and J. Altman. 1972. The effects of early hypo- and hyperthyroidism on the development of rat cerebellar cortex. I. Cell proliferation and differentiation. Brain Res. 44:13-23.

43. Aniello, F., D. Couchie, A.-M. Bridoux, D. Gripois, and J. Nunez. 1991 Splicing of juvenile and adult tau mRNA variants is regulated by thyroid hormone. Proc. Natl. Acad. Sci. USA. 88:4035-4039.

44. Salemi, G., D. Ferraro, and G. Savettieri. 1990. Triiodothyronine accelerates the synthesis of synapsin $I$ in developing neurons from fetal rat brain cultured in a synthetic medium. Neurochem. Res. 15:827-831.

45. Prieto, J. J., J. Rueda, M. L. Sala, and J. A. Merchan. 1990. Lectin staining of saccharides in the normal and hypothyroid developing organ of Corti. Dev. Brain Res. 52:141-149.

46. Gould, E., and L. L. Butcher. 1989. Developing cholinergic basal forebrain neurons are sensitive to thyroid hormone. J. Neurosci. 9:3347-3358.

47. Yusta, B., F. Besnard, J. Ortiz-Caro, A. Pascual, A. Aranda, and L. Sarlieve. 1988. Evidence for the presence of nuclear 3,5,3'-triiodothyronine receptor in secondary cultures of pure rat oligodendrocytes. Endocrinology. 122:22782284 .

48. Hubank, M., A. K. Sinha, D. Gullo, and R. P. Ekins. 1990. Nuclear triiodothyronine ( $\mathrm{T} 3$ ) binding in neonatal rat brain suggests a direct glial requirement for T3 during development. J. Endocrinol. 126:409-415.

49. Saneto, R. P., and J. De Vellis. 1985. Characterization of cultured rat oligodendrocytes proliferating in a serum-free, chemically defined medium. Proc. Natl. Acad. Sci. USA. 3509-3513.

50. Noguchi, T., and T. Sugisaki. 1984. Hypomyelination in the cerebrum of the congenitally hypothyroid mouse ( $h y t$ ). J. Neurochem. 42:891-893.

51. Kumar, S., R. Cole, F. Chiapelli, and J. De Vellis. 1989. Differential regulation of oligodendrocyte markers by glucocorticoids: post-transcriptiona regulation of both proteolipid protein and myelin basic protein and transcriptional regulation of glycerol phosphate dehydrogenase. Proc. Natl. Acad. Sci. USA. 86:6807-6811.

52. Tosic, M., A. Roach, J.-C. De Rivaz, M. Dolivo, and J.-M. Matthieu. 1990. Post-transcriptional events are responsible for low expression of myelin basic protein in myelin deficient mice: role of natural antisense RNA. EMBO (Eur. Mol. Biol. Organ.) J. 9:401-406.

53. Arquint, M., M. B. Tropak, P. W. Johnson, R. J. Dunn, and J. C. Roder. 1989. The primary structure of myelin associated glycoprotein suggests a role in myelination. in myelination and demyelination. Implications for multiple sclerosis. S. U. Kim, editor. Plenum Press, New York. 61-84.

54. Johnson, P. W., W. Abramow-Newerly, B. Seilheimer, R. Sadoul, M. B Tropak, M. Arquint, R. J. Dunn, M. Schachner, and J. C. Roder. 1989. Recombinant myelin-associated glycoprotein confers neural adhesion and neurite outgrowth function. Neuron. 3:377-385. 